\title{
Übersichtskarte der Eisenbahnen und Flussläufe von Elsass-Lothringéen.
}

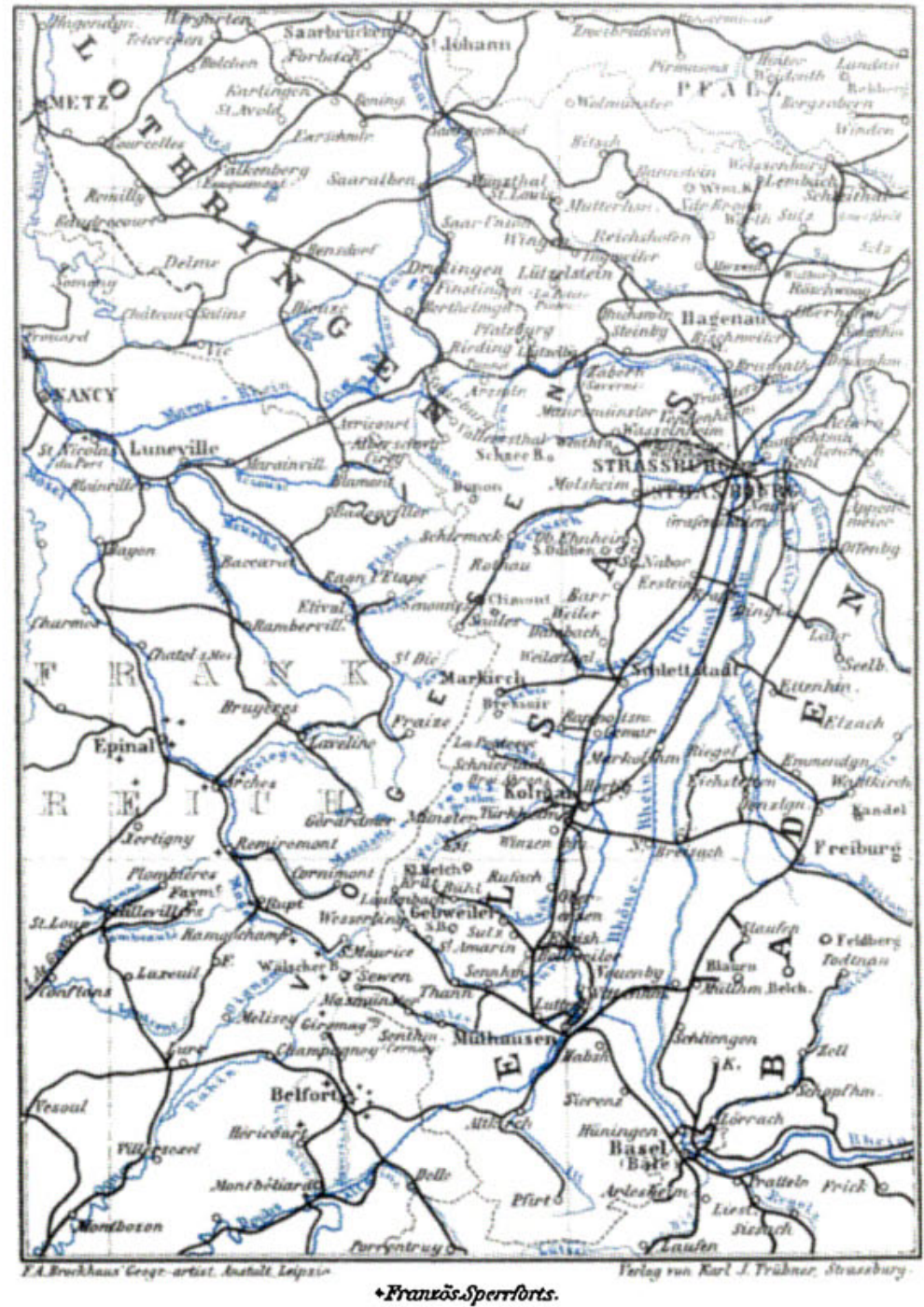





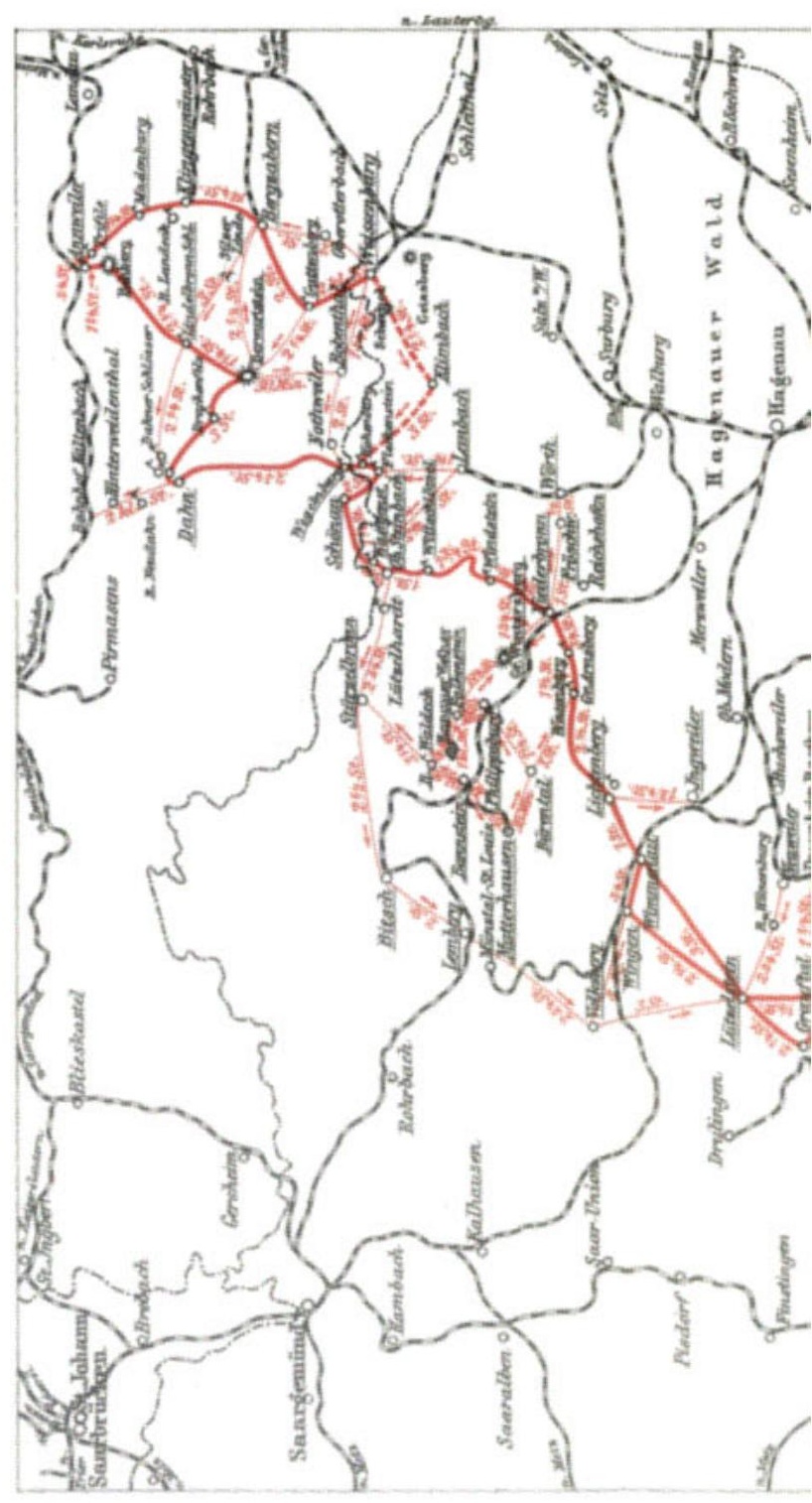




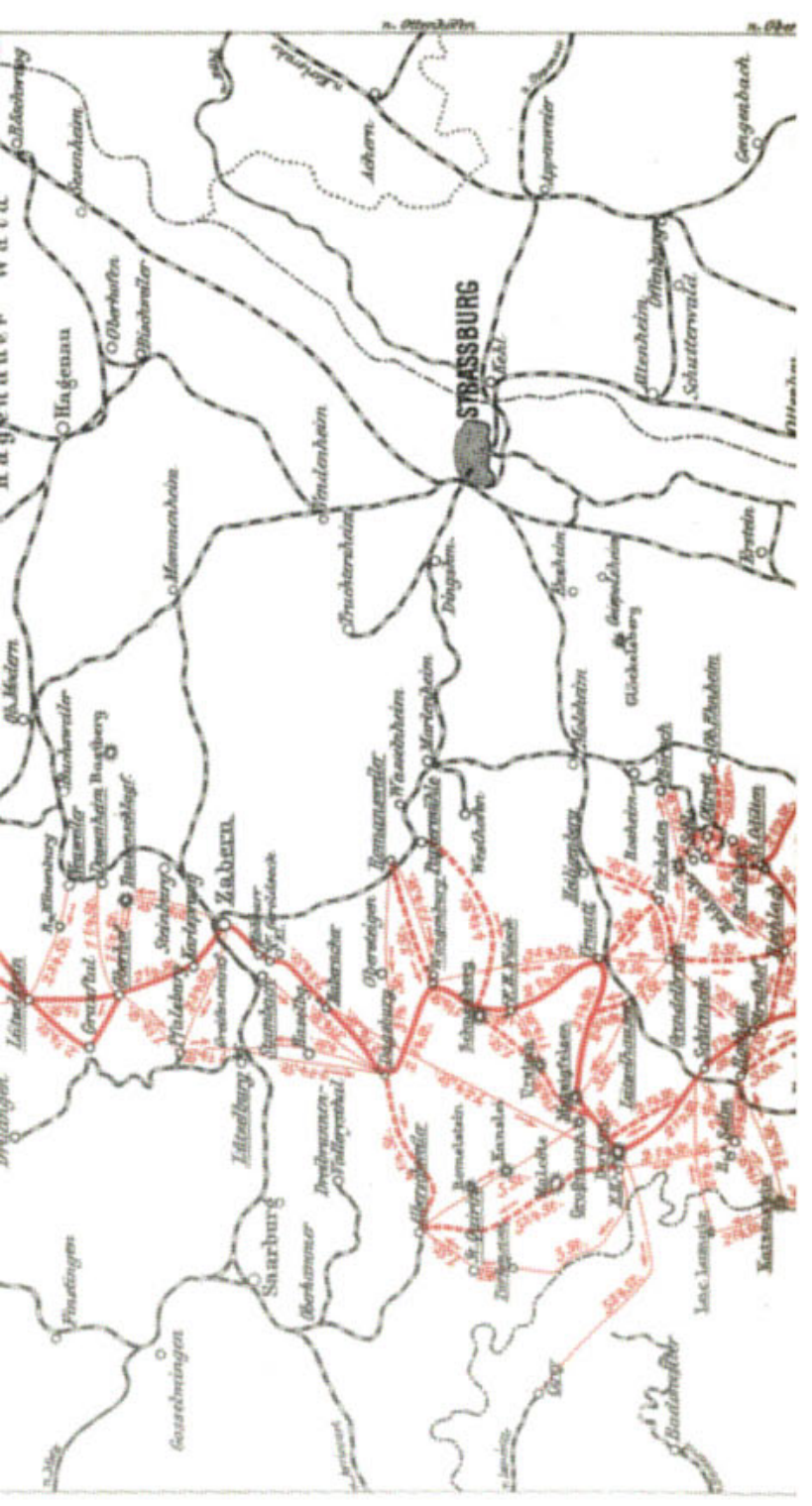




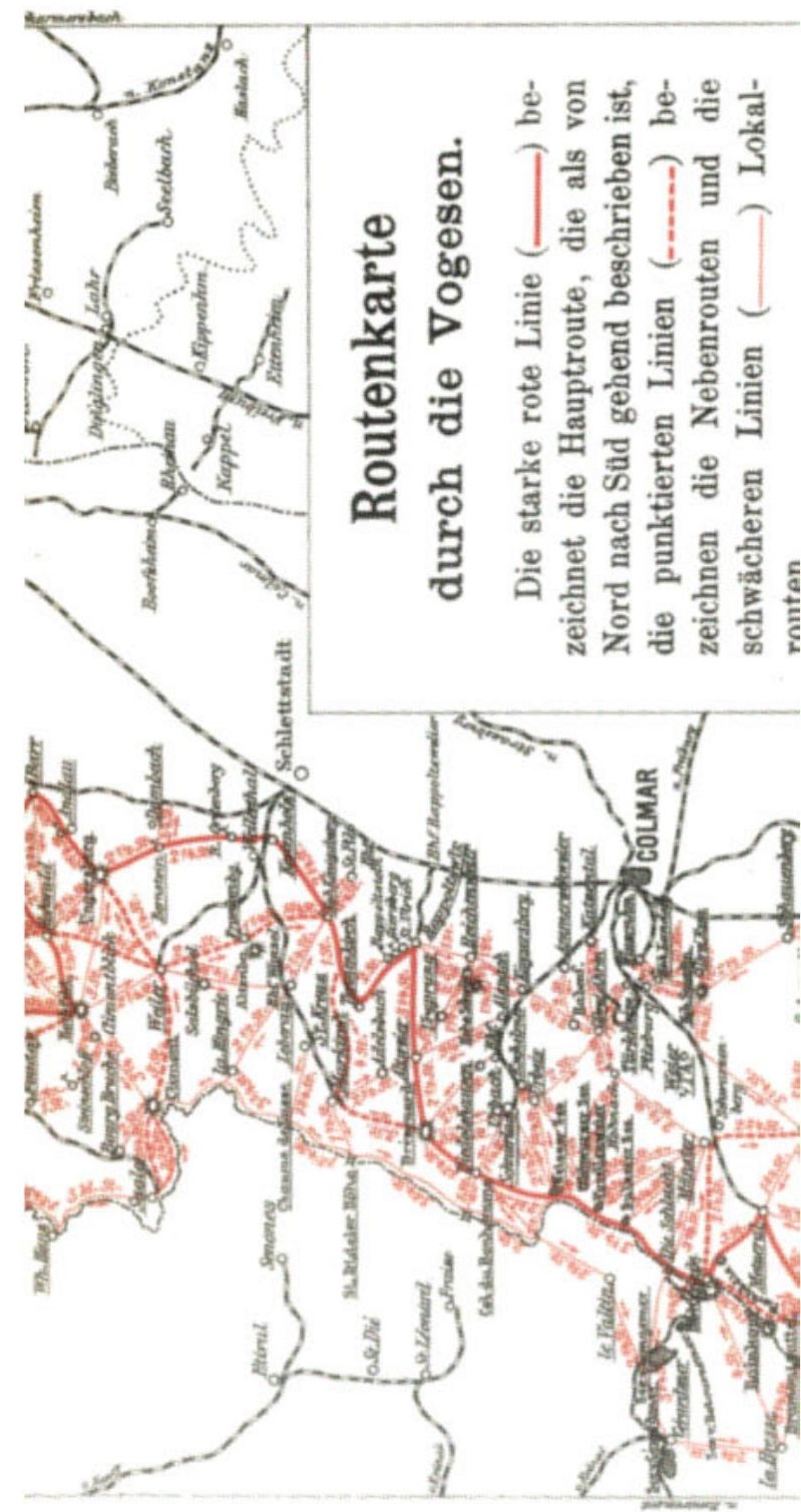





\section{FÜHRER}

DURCH

\section{DIE VOGESEN \\ $\operatorname{vos}$}

\section{CURT MÚNDEL.}

KLEINE AU BGAB DES BEISEHANDUUCHES

„DIE VOGBSEN".

MIT IU KARTEN UND PLANEN C.VD 6 ABBILDUNGEN IM TEXT.

FOMFTE, VIELFACH VERBESSERTE AUFLAGE

vor

DR. OTTO BECHSTEIN,

SCHRIFTFUHREK DES ZENTRALAUSSCHUSSES

DES VOGESENCLUBS.

\section{S'TRASSBURG}

VERLAG VON KARL J. TRÜBNER

1907.

Alle Rechte corhehalten.; 
Drey Behlouser auf einem Berge,

Drey Kirohen ant oinem Kirchhoffe,

Drey 8titt in einem Thal

Int das gasze Elenas aborall.

Altes Spricheort (Merian 1644). 
DEN

\section{PORSTMANNERI ELSASS-LOTHRINGRNS}

GEWIDMET. 
